\title{
3D Transient Spray Cooling Heat Transfer Simulation for Metallic Slabs of Various Alloys
}

\author{
Mohamed Elguerri ${ }^{1,2 *}$, Farid Belfodil ${ }^{2}$, Yassine El Guerri ${ }^{1,2}$, Abdelilah Bouragba $^{3}$ \\ ${ }^{1}$ Research Laboratory of Industrial Technologies, University of Tiaret, P.O. Box 78, Tiaret 14000, Algeria \\ ${ }^{2}$ Department of Mechanical Engineering, Faculty of Applied Sciences, University of Tiaret, Tiaret 14000, Algeria \\ ${ }^{3}$ Department of Mechanical Engineering, Faculty of Technology, University of Chlef, Chlef 2000, Algeria
}

Corresponding Author Email: mohamed.elguerri@univ-tiaret.dz

https://doi.org/10.18280/ijdne.150615

Received: 17 August 2020

Accepted: 8 October 2020

\section{Keywords:}

alloy, heat transfer, simulation, slabs, spray cooling, transient, tree-dimension, simulation

\begin{abstract}
Water spray cooling is widely used in many industrial processes to control the surface dissipation of a material ported at high temperatures. To predict heat transfer and obtain the rate of required temperature distributions of the surface, it is necessary to understand the basic spray cooling dynamics and a more precise estimation of the heat transfer rate. This paper is about a three-dimensional simulation to estimate the transient heat transfer obtained locally by water spray to reduce the temperature of heated metal. The use of water spraying is a practical and flexible process. It is possible to vary, in space, time, and in large proportions the flux of extracted heat and controls the density of the flow of water which is a key element and very simple to achieve. Globally, the aim of this study is to simulate the spray cooling of different metal slabs for various alloys (steel, cast iron, titanium, nickel) by mainly comparing cooling in maps of iso-surfaces and in curves (at starts and globally) obtained after estimation of the heat flux.
\end{abstract}

\section{INTRODUCTION}

These last years, the high heat flux applications have been widely studied as a promising solution for spray cooling.

Spray cooling of surfaces at very high temperatures is a very complex process. It involves the formation of many droplets from a nozzle, their continuous fragmentation with complicated dynamics, the nucleation of several vapor bubbles from the very hot surface, droplet-vapor bubble interactions and, heat transfer which results. This process became an increasingly required technology, found in several industrial applications with high heat flux. It is characterized by intense heat transfer and uniformity of heat dissipation.

Water spray cooling is widely used in metallurgical processes and heat treatment to control the temperature of the process. It is used statically, with fixed nozzles relatively to the cooled target, or dynamically, with moving. The static regime is typical for quenching systems intended for the heat treatment of fixed sheets and the dynamic regime is used in metal processing such as finish rolling and other applications.

Water spray cooling heat transfer coefficient of continuous casting for a heated steel plate, sprayed by water have been investigated [1]. The temperature of the surface of the plate was measured during its variation in the investigation. Experimental measurement data was used to calculate the heat transfer coefficient.

The lowest surface temperature possible far the being of spray evaporative cooling is determined experimentally to be a linear function of the impinging spray mass flux [2]. A conduction-controlled analytical model of droplet evaporation gives quite good agreement with experimental measurements at ambient conditions.

Various cooling methods investigated the heat transfer coefficients of copper, aluminum, and nickel billets heated, then cooled by water spray [3]. Measured temperature close to the surface was used to compute the heat transfer coefficient. Results allow analytical relation among the heat transfer coefficient and other operational spray cooling parameters.

An experimental investigation of hot metallic surfaces to study water spray heat transfer was performed in different regimes of the quench curve [4]. Heat transfer measure and hydrodynamic properties were made locally in the spray field area. Correlations established to serve up a universal approach to develop quench curves for industrial sprays.

An analytical spray cooling study of a hot surface was performed [5]. The radiation from the hot surfaces to the environment is the first study, the second is the heat transfer by conduction to the droplets of the sprayed water. Spray cooling heat transfer data of the proposed procedure was predicted within the experimental range mentioned.

A method has been developed for the general correlation of effective heat transfer for sprays impacting vertically downward on a high-temperature surface [6]. Heat flux correlation data in the film boiling regime was greatly improved by dimensional analysis. Heat transfer performance depends on spray mass flux and droplet diameter.

A three-dimensional numerical temperature field into a steel billet was analyzed with enthalpy formulation which depends on only two non-linear material parameters, thermal conductivity, and enthalpy [7]. The numerical simulation by finite element method aid to compute the temperature field and thickness of the solid shell using commercial software.

Cooling of hot surfaces using full cone sprays investigated to link spray properties at heat flux removed from the heated surface [8]. The influence of the mass flow on spray cooling heat flux and cooling efficiency is in qualitative agreement with other studies performed in similar conditions. Best performances are reached for spray having highest mass flux. 
The formulation of a model for heat transfer by finite volume to predict the temperature field in a continuous casting process under different conditions has been carried out [9]. The results of modeling were verified by the measured slab surface temperatures and a good agreement was achieved.

A great discord over the fundamental mechanisms of spray cooling heat transfer has been confronted due to complexity of this process [10]. Reliable correlations based on spray parameters are needed and dividing energy between singleand two-phase mechanisms at higher wall temperatures and mechanisms by which CHF come also needs further studies.

Water spray cooling is an efficient technology used in hightemperature surfaces in the metal production and processing industry [11]. Below a specific surface temperature, the heat transfer coefficient shows a strong dependence on temperature. The results give a correlation of the heat transfer coefficient which totally depends on temperature difference.

Experimental studies and numerical simulations have been carried on multiphase sprays for cooling applications [12]. Studies divulge that the heat transfer of multiphase sprays and efficiency of impact to be highly dependent on spray droplet size, air-to-liquid loading, and nozzle distance from target surface. In the view of heat transfer, if smaller is the droplet size, better is spray heat transfer efficiency.

The duty cycle is the major parameter of more accurate control of the cooling process [13]. Small duty cycles upgrade heat removal by phase-change. The formation of a thin liquid film is affected by larger duty cycles which evolve to continuous spray improving thermal response of cooling but hit the performances of the system. Intermittent spray cooling enables the design of thermal cooling management systems.

A predictive model of heat and mass transfer allows a favorable comparison which has been validated by the experimental results [14]. Parameters sensitivity were analyzed to get the influence of them on the surface temperature distribution. The heat transfer produced by droplet-film impact and film-surface convection are dominant in the condition that the surface is not superheated, but when the surface is superheated, the boiling effect increases rapidly.

Often in the literature, the process of spray cooling is a very basic level considering the dynamic phenomena involved in the impact of each drop of spray [15]. However, the interaction between drops modifies these phenomena and does not allow the spray to be qualified as the sum of individual effects. These phenomena include partial deposition of incident mass; the appearance of secondary droplets due to fragmentation mechanisms; and extraction and dissipation of the heat.

Spray cooling is much used in several domains and in hot surfaces cooling enclosed hot strip mill [16]. It plays an important role in metal production and industrial process, for very high-temperature steel strip casting and final microstructure optimization after hot rolling. A jet of water drops carried by gas is sprayed toward a hot surface to be cooled.

Control parameters such as spray cooling of a metal plate for different alloys, speed of development, flow rate have the same overall influence on the heat transfer defined by "boiling curves". But, by using a flat spray ensuring homogeneous atomization and high drop rates, the overall transfer is significantly improved which allows faster and more stable cooling kinetics over a large temperature range [17].

The displacement of the target, the variation of the cooling section, the position of the nozzles, and the heterogeneity of distribution of droplets leads to abnormal and non-uniform cooling conditions. It is therefore important to define the effect of these parameters on the intensity of heat transfer during the cooling process of steel sheets [18].

A study reviews two-part of spray cooling. The first study the relatively high-flux with low-temperature mechanisms, the second examine the relatively high-temperature transition boiling and film boiling regimes. Conflicting results point to a need for future test work that must be achieved systematically using many fluids with very different thermophysical properties and wide ranges of operating conditions [19].

A critical review of spray cooling by two levels is presented; by spray and by droplets [20]. The critic of the level of spray is center on the spray cooling performance which is a function of fluid properties, flow and surface conditions, and nozzle position. The droplet level study is based on the impact of droplet flow, on film flow which is the key to the spray cooling mechanism.

For determining how cooling effect of copper alloy changes with roughness, type of water, and type of nozzle, several experiments were performed on this heated alloy plates with various combination of parameters [21]. Results of the cooling rate were studied on the unidimensional model. The results were controlled for the two types of nozzles by experiments.

High-speed visualization and image processing of a heated target is studied to see the dynamic behavior of the liquid film produced by spray impact [22]. If the spray characteristics remain constant, the efficiency of spray cooling decreases. On the other hand, cooling is more efficient of the heated surface if the jet is modified by larger sizes and speeds of drops.

A conduction heat transfer simulation in a Titanium alloy slab was achieved [23]. The slab sprayed by water on its upside, must cool to reach the saturation temperature of the water and is in thermal interaction with the surrounding medium of its all sides by convection and radiation. The simulation is based on numerical solving in three dimensions of the nonlinear transient heat equation, using commercial software to obtain a temperature distribution inside the slab.

Spray cooling is a very efficient technology, surpassing all other conventional cooling methods. This process is extremely complex, thus most design rules to date are highly empirical in type. The review has the goal of sum up some of these recent advances and to establish a scope for the future development of more reliable and universal physics-based correlations to describe quantities involved in spray cooling [24].

\section{PROBLEME STATEMENT}

To cool hot metal surfaces, there are three interesting processes: film cooling, spray cooling, or immersion cooling. Regardless of the type of cooling performed on the hot surface, the temperature exceeds $600^{\circ} \mathrm{C}$, firstly, a stable vapor film is established. At the surface, as soon as said Leidenfrost temperature is reached, the vapor film formed breaks off and there begins its partial evaporation.

The problem posed is to simulate the process of heat transfer inside a solid slab for a period of time during its cooling by water spray to determine the temperature distribution at any point of the solid in question.

Four materials were selected in our study which are A92020 steel, Fe1020 Iron, AZ31 aluminum alloy, and Ti6Al4V titanium alloy. These materials are selected for their wide applications and for some particularity like their thermophysical, chemical, and mechanical qualities. 
The goal of this study is to establish for each material threedimensional temperature distribution maps $T(x, y, z, t)$ in the slab of dimensions $x \times y \times z=1000 \times 100 \times 40 \mathrm{~mm}^{3}$ in transient regime with mixed boundary conditions that we will define later. This position is similar to the production conditions of the continuous casting process, the metal rolling process, the quenching process in metallurgy, and many other processes. The proposed study attempts to explain the behavior of the spray cooling heat transfer process.

In summary, the problem becomes to solve this equation:

$$
\begin{aligned}
\rho(T) \cdot C(T) \cdot \frac{\partial T}{\partial t}=\frac{\partial}{\partial x}\left(\lambda(T) \cdot \frac{\partial T}{\partial x}\right)+ & \\
& \frac{\partial}{\partial y}\left(\lambda(T) \cdot \frac{\partial T}{\partial y}\right)+\frac{\partial}{\partial z}\left(\lambda(T) \cdot \frac{\partial T}{\partial z}\right)
\end{aligned}
$$

Determining the temperature distribution will make it possible to follow its evolution and optimize the heat transfer in the plate during the spray cooling process. This optimization provides the conditions that can help improve the productivity and the material quality of the product. To achieve this objective, we will define simulation conditions which will allow determining the desired spatial temperature as a function of time of any point of the plate under specific conditions similar to those of the practice.

The cast irons are heated to a temperature of about $1300 \mathrm{~K}$ to be cooled in successive stages to ambient conditions. The traditional cooling method is based on a sequential tuning of air jets, mists, and water sprays. With the increasing demand for production rates, water spray coils tend to replace other quenching techniques. This technique involves passing the plate through a series of cooling units made up of water sprays. The methodology followed studies by numerical simulation of the thermal behavior of the plate based on experimental characteristics of water sprays.

\section{SIMULATION}

Numerical simulation is a powerful tool to study physical problems. In our case, we are studying the spray cooling heat transfer for some materials.

A calculation program was written by a computer language running on a computer that translates from a mathematical model that describes a physical phenomenon is called a digital simulation. Numerical simulation is essential to study the behavior of physical phenomena whose mathematical models are very complex to arrive at analytical solutions, which is the case of many nonlinear problems.

Many secondary phenomena are the consequence of spray cooling which is very complicated to model and the complexity increases when all these models are simultaneously simulated. Boiling in spray cooling complicates modeling and very little literature is available on this subject. The experimentation on which the simulation is based is difficult due to the problem of measuring the velocity and diameter of the droplets and the experimental capture of the wall film thickness.

COMSOL Multiphysics v3.5a software was used for its powerful finite element partial differential equation solver, also used to solve some physical problems. From our side, we chose it for its efficiency to solve complex thermal problems.

\subsection{Concept}

The use of COMSOL Multiphysics software in this study is for its specificity to make it possible the coupling of different phenomena, so as to describe multiphase phenomena.

The "Heat Transfer" module is an optional module that extends the possibilities of COMSOL with customized user interfaces and optimized functionality for heat transmission analysis. They have been developed for a wide audience, including researchers, developers, teachers, and students.

Heat transfer is involved in almost all types of physical processes and can be the limiting factor for many of them. Its study is often of vital importance and requires powerful analytical tools. In addition, heat transmission often appears coupled with other physical phenomena, which can be addressed in COMSOL. The thermal modulus supports all the fundamental mechanisms of heat transfer conduction, convection, and radiation. We have most often neglected the radiation, thermal equations solved by the simulator are then

$$
\begin{gathered}
\nabla \cdot(-\lambda \cdot \nabla T)=Q \\
-n \cdot(-\lambda \cdot \nabla T)=q_{o}+h \cdot\left(T_{\text {inf }}-T\right)
\end{gathered}
$$

\subsection{Initial and boundary conditions}

The heat equation accepts two types of boundary conditions: a specified temperature and a specified heat flux. The first prescribes the temperature at the entire body:

$$
T=T_{0}
$$

While the second specifies a heat flux:

$$
q^{\prime \prime}=n \cdot q^{\prime \prime}
$$

where, $q^{\prime \prime}$ is the total heat flux vector:

$$
q^{\prime \prime}=-\lambda \cdot \nabla T
$$

$n$ is a normal vector at the border and $q_{0}{ }^{\prime \prime}$ is the heat flux, normal at the boundary too.

A thermal simulation of spray cooling process using a numerical resolution of the transient nonlinear threedimensional heat equation from the initial condition and specific boundary conditions for a titanium alloy Ti6Al4V metal plate initially brought to high temperature using simulation software to predict the desired thermal parameters in terms of temperature and heat flux [25].

Note that when heat transfer by convection is active, the condition at the boundary of heat flux is of the mixed type, or Robin, rather than a condition at the pure Neumann boundary. The heat flux $q_{0}$ " is normally a sum of the contributions of the different heat transfer processes. It is often convenient to divide the heat flux boundary condition into:

$$
-n(\lambda \cdot \nabla T)=q^{\prime \prime}{ }_{0}
$$

It is the amount of waste heat dissipated as a heat flow. 
Initially, the temperature at any point of the (uniform) domain, represented by the function $T(x, y, z, t)$, is fixed at time $t=0 \mathrm{~s}$, defines the initial condition:

$$
T(x, y, z, 0)=T_{0}(x, y, z)=T_{i n i}
$$

This temperature is obtained from the melting temperature of each material, reduced by a certain specific temperature to prepare the cooling process by natural convection and by radiation to the sides faces and the lower face of the outside of the plate when it leaves the furnace to the spray cooling zone.

The area of the plate is parallelepiped in shape with six faces, each of which is subject to the condition at the appropriate boundary.

We designate:
1) Front face,
2) Right side face,
3) Under face,
4) Upper face,
5) Left side face,
6) Back face.

The boundary conditions applied in our problem are of the heat flux type specified. We have two types of imposed flux: the first on the upper face and the second on the other surfaces.

For the condition at the boundary of the upper face (4) for $z$ $=100 \mathrm{~mm}$, we find the boiling convection with phase change characterized by a water film in boiling at the temperature $100^{\circ} \mathrm{C}$, the convection of the air and radiation which are governed by the equation:

$$
\begin{gathered}
q_{0}^{\prime \prime}=q_{\text {spra }}^{\prime \prime}+q_{\text {conv }}^{\prime \prime}+q^{\prime \prime}{ }_{\text {radi }} \\
-\left.\lambda(T) \cdot \frac{\partial T}{\partial z}\right|_{z=z, u p}= \\
h_{D} \cdot\left(T-T_{e b u}\right)+h_{a} \cdot\left(T-T_{a m b}\right)+\sigma \cdot \varepsilon \cdot\left(T^{4}-T_{a m b}^{4}\right)
\end{gathered}
$$

$\sigma=5,67 \cdot 10^{-8} \mathrm{~W} /\left(\mathrm{m}^{2} \cdot \mathrm{K}^{4}\right)$ and $h_{D}$ is the two-phase heat transfer coefficient obtained from the previous hydrodynamic calculations (it is assumed to be uniform over the entire sprayed surface):

$$
h_{D}=\frac{q^{\prime \prime}{ }_{s p r a}}{T_{s u r}-T_{e b u}}
$$

$q^{\prime \prime}$ spray is the heat flux in water spray cooling and can be evaluated using the Bratuta and Ivanovsky equation [26]:

$$
q^{\prime \prime}{ }_{\text {spra }}=4.6 \cdot 10^{6} \cdot(\Delta P)^{0.1}\left[g_{\max }(x, y)\right]^{0.4}
$$

After calculations of hydrodynamic parameters [25], the necessary results of the coefficient $h_{D}$ are obtained. The plate emits radiation to the surrounding ambient medium at a temperature of $25^{\circ} \mathrm{C}$ with nonlinear exchange property, knowing that $h_{a}$ the heat transfer coefficient by natural air convection depends also on the temperature of the slab.

$$
h_{a}=f(T)
$$

the emissivity $\varepsilon$ depends on the temperature for each material.

$$
\varepsilon=f(T)
$$

\subsection{Selected study points}

Four points on each face of the simulation slab were selected. These points are represented in Table 1 as shown in Figure 1.

Table 1. Coordinates of selected points

\begin{tabular}{ccccc}
\hline \multirow{2}{*}{ Point } & \multicolumn{3}{c}{ Coordinates } & \multirow{2}{*}{ Position } \\
\cline { 2 - 4 } & $\boldsymbol{x}, \boldsymbol{m}$ & $\boldsymbol{z , \boldsymbol { m }}$ & $\boldsymbol{y , \boldsymbol { m }}$ & Upper center \\
P1 & 0.5 & 0.1 & 0.2 & Upper frontal center \\
P2 & 0.0 & 0.1 & 0.2 & Upper corner \\
P3 & 0.0 & 0.1 & 0.0 & Upper lateral center \\
P4 & 0.5 & 0.1 & 0.0 & Lower center \\
P5 & 0.5 & 0.0 & 0.2 & Lower frontal center \\
P6 & 0.0 & 0.0 & 0.2 & Lower corner \\
P7 & 0.0 & 0.0 & 0.0 & Lower lateral center \\
P8 & 0.5 & 0.0 & 0.0 & \\
\hline
\end{tabular}

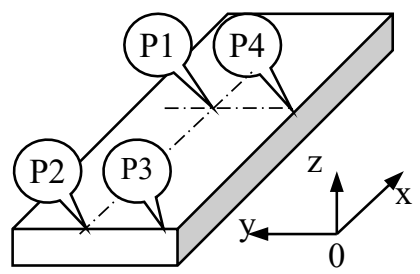

Figure 1. Selected study points: $\mathrm{P} 1$ to $\mathrm{P} 4$ for the upper side and $\mathrm{P} 5$ to $\mathrm{P} 8$ for the down side

\section{RESULTS AND DISCUSSION}

The simulation of water spray cooling of the selected metal alloys is analyzed. It is based on the three-dimensional heat equation completes by the set of boundary conditions that specify the problem treated.

The used software provides the curves making it possible to follow the evolution of the heat transfer for the various regimes encountered during cooling. The characterization of the software also makes it possible to map the heat flux during the cooling process for all the materials studied.

From the numerical investigation data carried out, the kinetics of cooling on the product studied under controlled conditions can lead to the determination of the physical characteristics of the product (density, specific heat, thermal conductivity) and the determination of the means coefficients of heat transfer.

The software used made it possible to solve the equation and thus, to build a cooling model. Once this model is built, we can study the impact of any unstudied cooling condition on the kinetics of temperature drop at any point in the product.

Temperature control and cooling control are, in many industrial applications, key parameters for manufacturing quality and product lifespan. Spray cooling is commonly used in processes involving high temperatures where it is often difficult to characterize the flows and their distribution.

We will start to analyze groups of maps for each material. Thus, for each group, we have one figure for each material. Then, from Figure 2 we will move on to other groups of figures constituting characteristic curves to be analyzed.

Figure 2 shows the spatial variation of the transient temperature in the A92020 steel slab. We have two illustrations, one $(a, b)$ is solid in two views, the other $(c, d)$ is iso-surfaces with each one in the top and bottom views. 


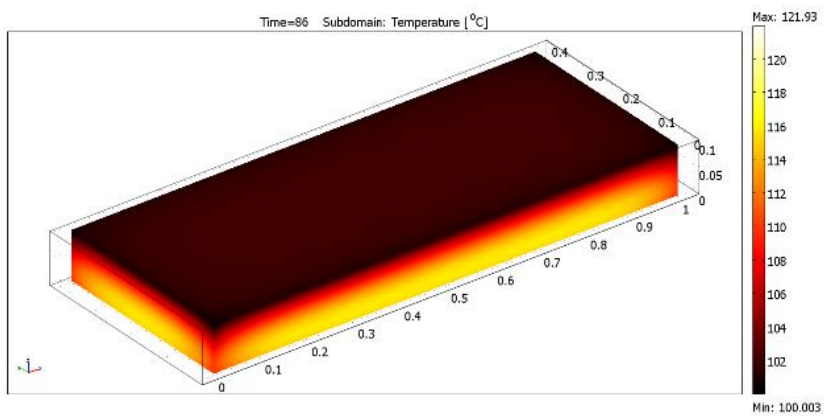

(a) top view in volume

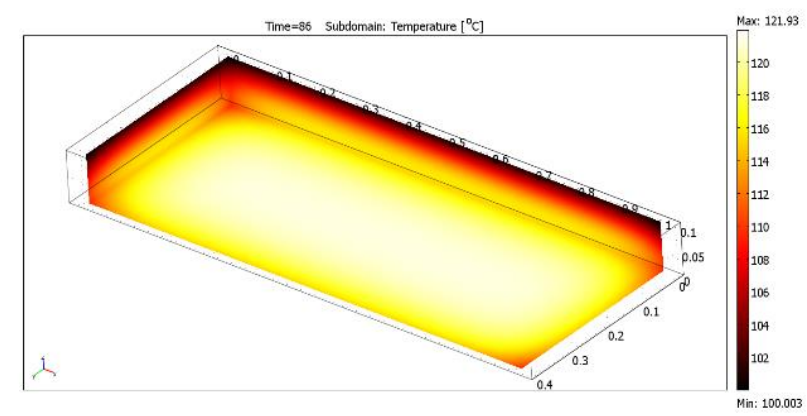

(b) bottom view in volume

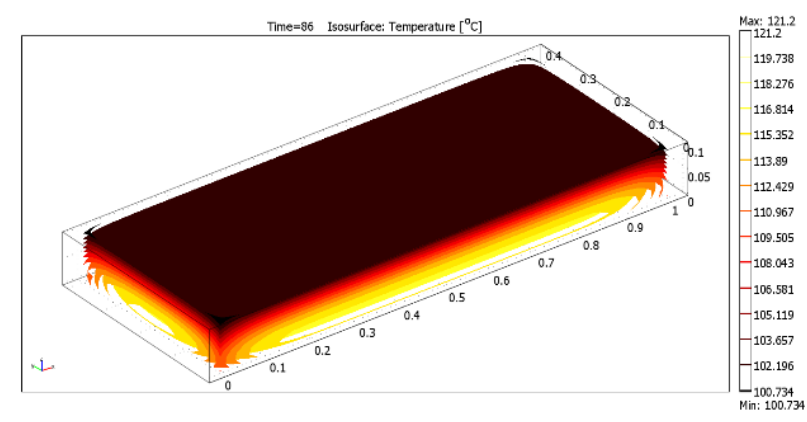

(c) top view in iso-surfaces

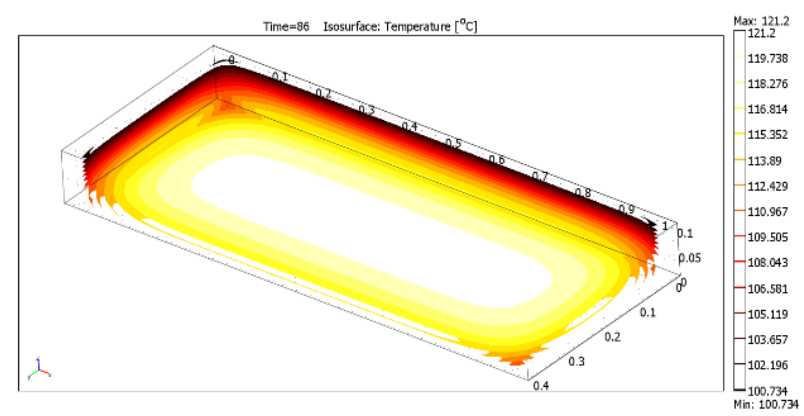

(d) view from below in iso-surfaces

Figure 2. Transient spray cooling simulation map $T=f(t)$ in A92020 steel slab in three dimensions (3D)

Heat transfer occurs from the bottom to the top in the form of iso-surfaces with uniform temperature ranging from 100.73 to $121.20^{\circ} \mathrm{C}$, at process stability. On the lower face, there are several concentric iso-surfaces where each one envelops the one below with a higher temperature than it, ranging for example from 121.20 to $110.97^{\circ} \mathrm{C}$ with eight iso-surfaces. The stability temperature is in the vicinity of $100^{\circ} \mathrm{C}$ which represents the upper iso-surface facing the spray.

The same illustration is adopted in Figure 3 to also show the spatial variation of the transient temperature in an AZ31 aluminum alloy slab. Volume illustrations are abandoned in favor of iso-surfaces which are crystal clear. From bottom to top, the iso-surfaces take temperatures from 100.68 to $118.56^{\circ} \mathrm{C}$ at the stability of $\mathrm{AZ3} 1$ with heat dissipation to the upper face by the appearance of two iso-surfaces, the least hot in the center and around the hottest. Similar to Figure $2 d$, in Figure $3 b$ we see on the lower face several concentric isosurfaces where one envelops the others at temperatures ranging for example from 118.56 to 108.34 for nine isosurfaces.

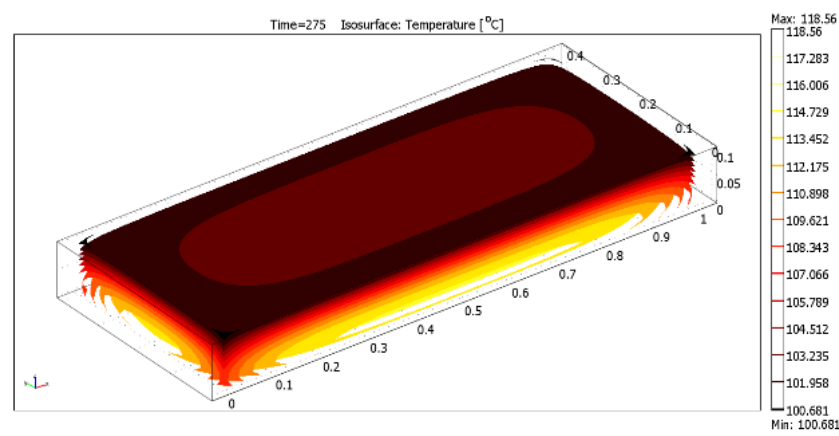

(a) top view

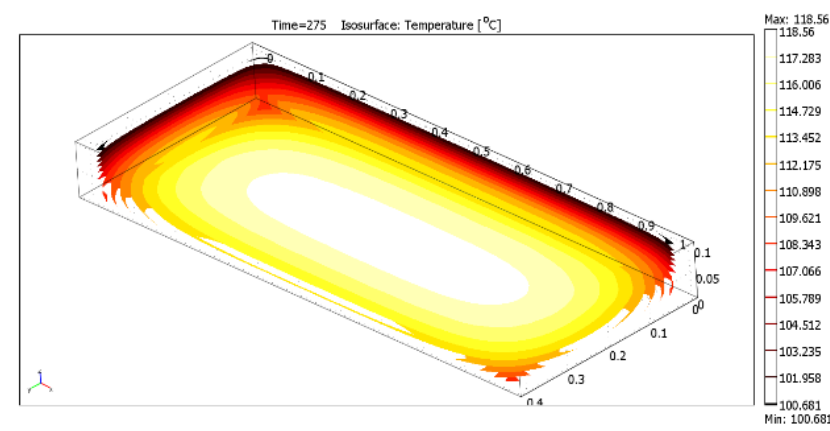

(b) bottom view

Figure 3. Iso-surfaces transient cooling simulation map in AZ31 aluminum alloy slab

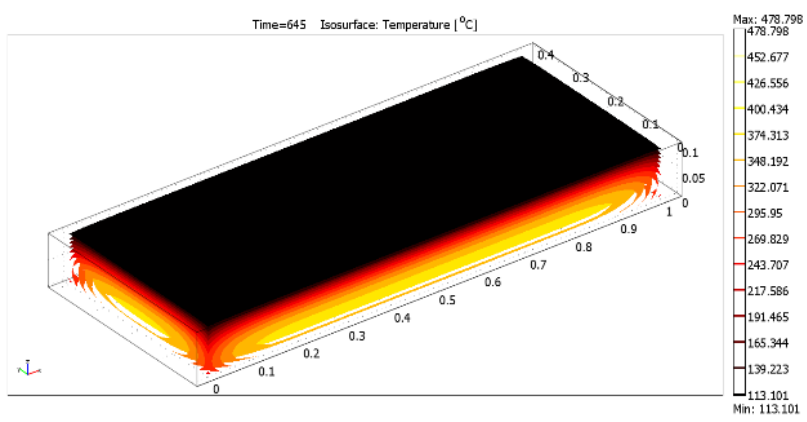

(a) top view

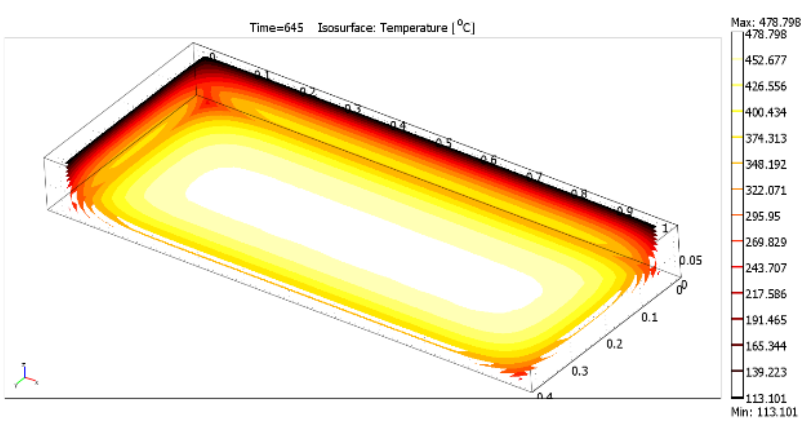

(b) bottom view

Figure 4. Iso-surfaces transient cooling simulation map in Ti6Al4V titanium alloy slab 


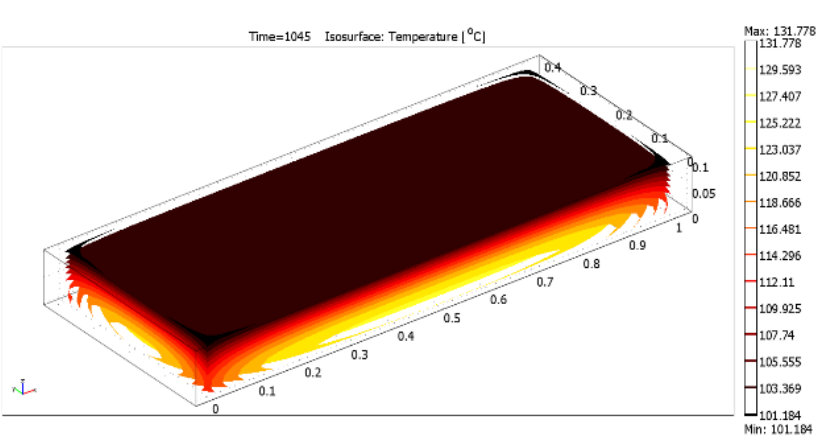

(a) top view

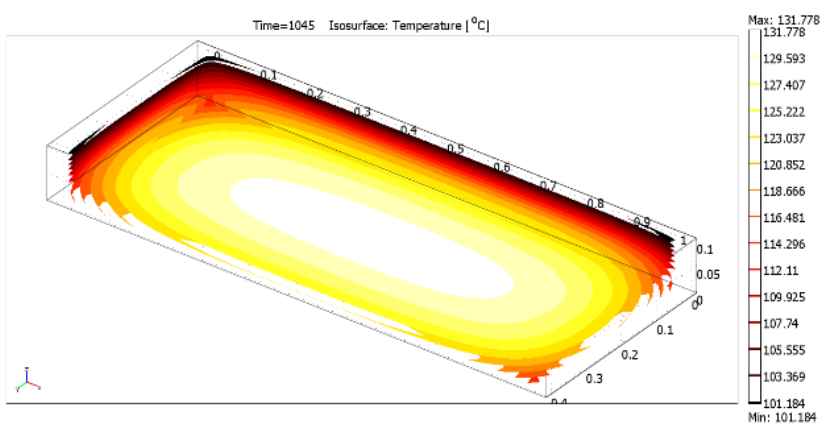

(b) bottom view

Figure 5. Iso-surfaces transient cooling simulation map in Fe1020 iron alloy slab
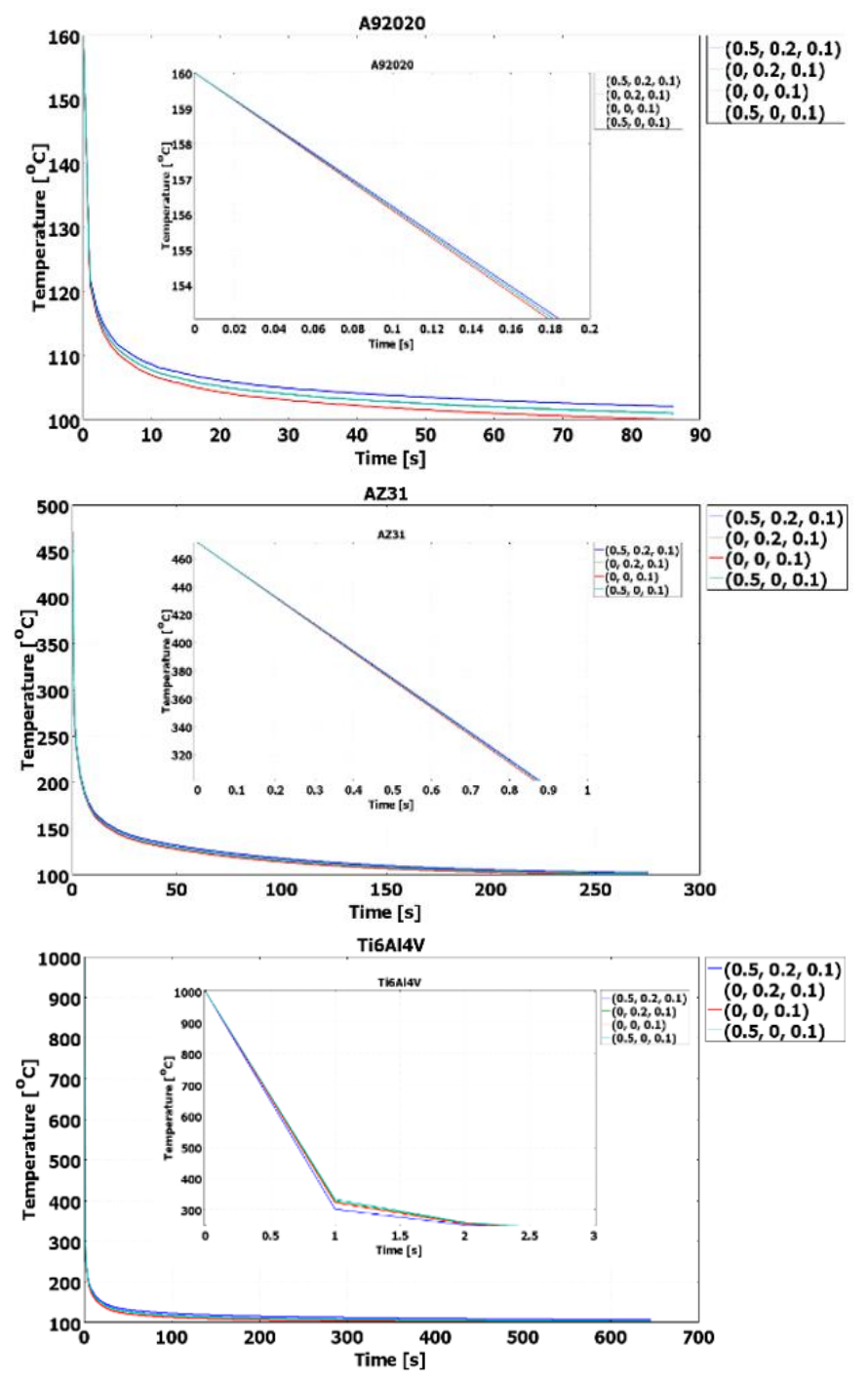

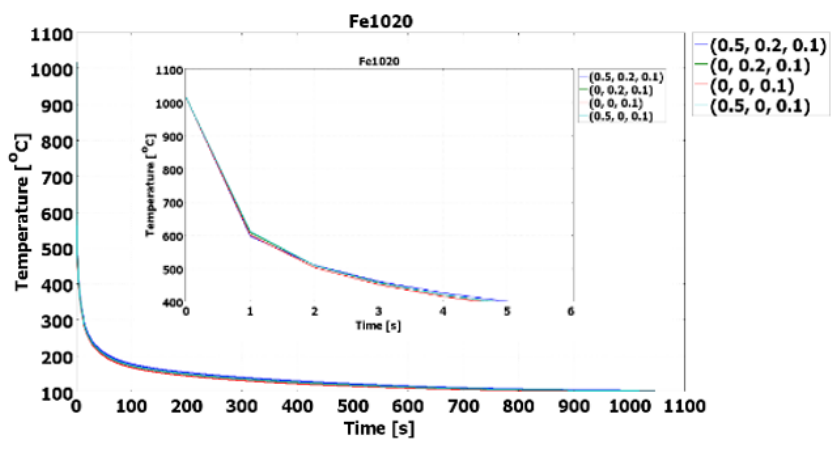

Figure 6. Comparisons of top face temperatures history for the different alloys
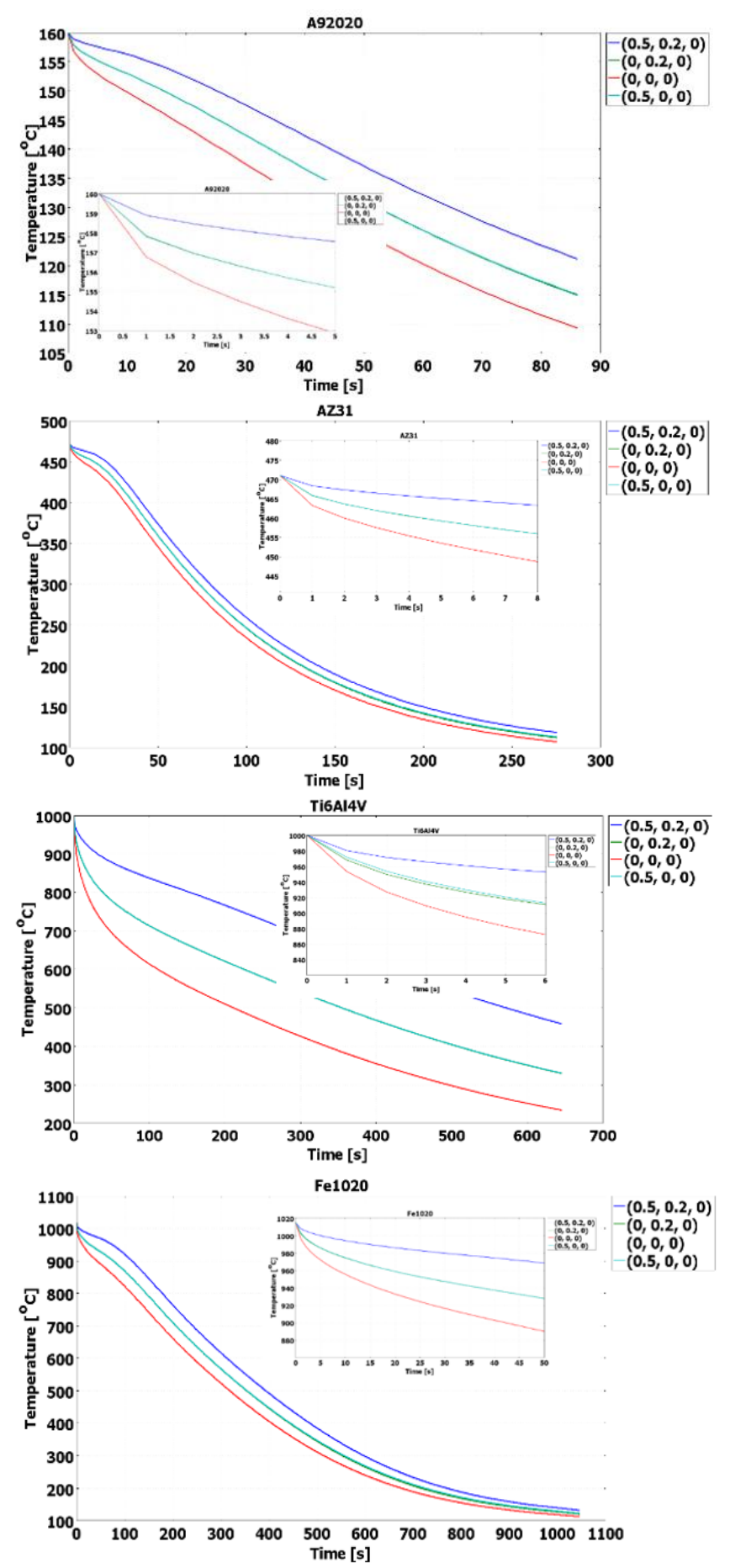

Figure 7. Comparisons of bottom face temperatures history for the different alloys 

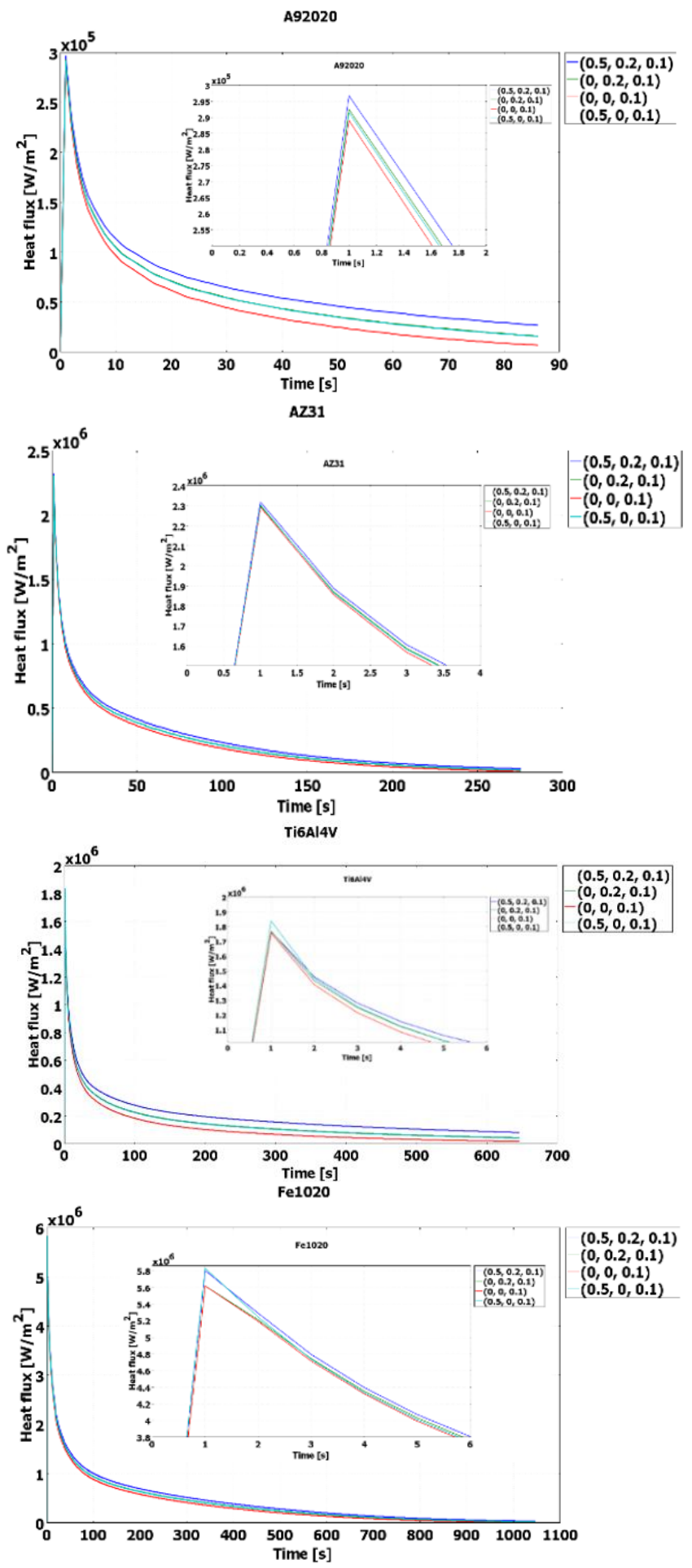

Figure 8. Top face transient heat flux $q^{\prime \prime}=f(t)$ for the different alloys

A similar configuration is observed for the other materials; in Figure 4 for the titanium alloy, the temperature ranges from 113.10 to $478.80^{\circ} \mathrm{C}$ but from 101.18 to $131.78^{\circ} \mathrm{C}$ for the iron alloy in Figure 5.

The history of transient temperatures of the upper face for the different alloys is plotted in Figure 6. There are two groups of curves for each material. The group of small curves represents the local amplification (the start) to a detailed scale of the peak for maximum temperatures in the big curves. We note the very rapid fall in temperature at the upper face of all materials. We also note that the temperature variation differs over time and by the manner from one material to another. For the first two materials, the fall is linear, but it changes the slope for the other two materials.

In the same way, Figure 7 groups together the curves of the history of transient temperatures of the lower face for the different alloys. Also, for each material two groups of curves are represented. The small graphs represent the local amplification which gives the detail of the maximum of the temperatures of historical curves. The temperature drop is relatively slow on the underside for all materials with suitable slopes. The beginning of the falls takes on a similar but specific appearance for each material.
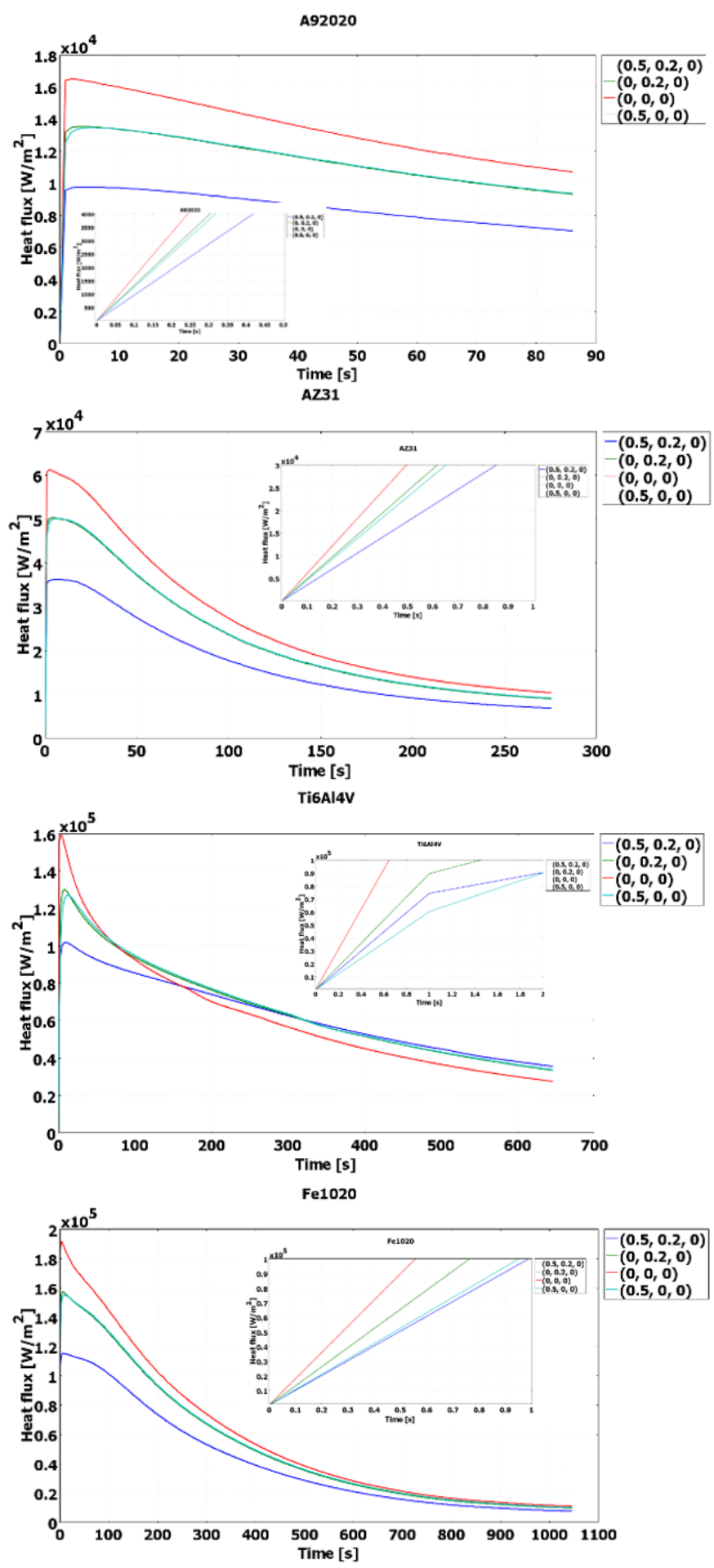

Figure 9. Bottom face transient heat flux $q^{\prime \prime}=f(t)$ for the different alloys 
Figures 8 and 9 follow the same principle as the two previous figures which is showing the variation of heat flux for each side of the metal slabs for the different materials. An analysis of the heat fluxes extracted from the curves in these figures shows high surface flux densities of nearly $6.10^{6} \mathrm{~W} / \mathrm{m}^{2}$ for the upper faces of the Fe1020 alloy in direct contact with the spray.

For the lower face, fluxes of the order of $1,8.10^{4} \mathrm{~W} / \mathrm{m}^{2}$ are recorded for the $\mathrm{A} 92020$ steel, $7.10^{4} \mathrm{~W} / \mathrm{m}^{2}$ for the aluminum alloy AZ31, $1,6.10^{5} \mathrm{~W} / \mathrm{m}^{2}$ for the titanium alloy Ti6A14V, $10^{5}$ $\mathrm{W} / \mathrm{m}^{2}$ for the nickel alloy, and $2.10^{5} \mathrm{~W} / \mathrm{m}^{2}$ for the iron alloy. It is noted that the most important heat flux is that of the iron alloy, then comes that of the aluminum alloy, then the other materials under the same simulation conditions.

\section{VALIDATION}

In order to give a referential aspect to our simulation results and to give them a credit, we take works applying similar experimental or numerical conditions of investigation or which are close to the conditions of our study and we try to establish a critical comparison of our curves versus those we referenced to make our results valid.

A brief review of some works in the literature will allow us to clearly see the relevance of our results and to confirm their validity. Many references have been indicated, among which we have selected a few, others remain without citation despite their relevance and their close link with our results.

History of measured transient temperature for a full cone of a round spray impinges on stationary hot steel surface was used to compute surface heat flux [27]. The cooling curve shows an illustration of transient temperature profile. These profiles are fully like our temperature histories in Figure 7.

Increasing spray cooling using different coolants which improve the rate of heat removal by creating a high heat transfer zone on heating plate [28]. The curves of the variation of surface temperature over time are very similar to ours.

Hot surface spray-cooling rate experiments of a small metal specimen show both the fundamental validity and limitation of the theory [29]. A typical temperature-time curves are provided which illustrates the relation between temperature and time observed during the cooling process.

Generic history of the midplane temperature of a hot plate in aluminium cooled by water sprays, registered and analyzed in order to obtain the wall temperature curves [30] is shown schematically look the same as those in Figure 7 for temperature and Figures 8 and 9 for the heat flux.

The effect of the orientation of a hot test plate on heat transfer during spray cooling was studied. An example of curves was computed from surface temperatures [31] and some classical curves are traced as in our case.

The temperature field is shown by figure map in the crosssection at the straightening point using the new nozzle and a specific water flow rate nozzle [32]. This map is very similar to our temperature field maps (Figure 2 to 5 ) by bottom faces.

The temperature histories at selected points were compared with the temperature distributions obtained from the inverse solution [33]. Results are in good agreement with the temperatures measured during the cooling. Our approach, also adopted in Figure 1, allowed us to obtain comparable results.

A comparison of the measured temperatures with the predicted temperatures at the measured locations is shown by plotted curves of the prediction [34] which are analogous in shape to our curves of the same kind.

Experimented and computed temperature profile above heated flat disk up the center of the plate [35] shows the rapid decrease in temperature as those in Figure 6 with a distance from the heated surface but not with time as in our case.

Comparison of the predicted and measured temperatures was determined with an acceptable accuracy of the prediction [36]. Most of the curves obtained are comparable to ours in condition and look.

Comparison of temperature curves of different measures for a smooth surface and rough/real surface is shown. The influence of the initial wall temperature on the dependence of the surface temperature on time for a higher mass flux density is plotted [37] and its profile is broadly like ours.

Several surface temperatures versus time curves showing the results of the transient spray cooling confirm the excellent agreement between experimental results and theoretical predictions [38]. Comparing some of these curves to ours, there clearly seen similarity, thus reinforce the validity of our results.

Take from, for example, Figure 9 of the history curves for aluminum and titanium alloys, we see the same aspect of the descending curves indicating an analog behavior of cooling. However, major deviations are observed, due to the facts of the investigative conditions which are not quite the same.

We record a good agreement between the temperature and heat flux curves of our simulation results compared to those of the references cited in the literature that we have reviewed. The comparison is visibly clear, thus providing a certain validity of our results.

\section{CONCLUSIONS}

Cooling a hot surface with a water jet is convenient and very flexible. It is possible to vary, spatially and temporally and in large proportions, the heat flow extracted from a very hot slab by controlling the density of the water flow, which is very simple to achieve. A water spray cooling plant may consist of:

- either only mechanical sprayers; it is then possible to achieve uniform thermal flux densities over large areas while ensuring uniformity of the spray rate,

- or mechanical sprayers in which airflow is associated or pneumatic sprayers; the two systems producing a mixture of air and sprayed water; it is then possible to obtain higher heat flux densities than previously.

Temperature control of cooling is, in many industrial applications, a key parameter for product quality and production profitability. Although water spray cooling is widely used for processes involving high temperatures, it is still difficult to characterize the intensity and distribution of cooling heat flows.

The aim of this study is to simulate the variation of temperatures in spray cooling of different metal slabs for various alloys (steel, cast iron, titanium, nickel) by comparing cooling in iso-surfaces maps and in curves obtained after estimation of the heat flux.

The cooling of thick water spray slabs is investigated by simulation, taking into account different materials. The obtained results are presented in the form of maps and curves to express the intensity of temperature variation in the slabs.

The use of iso-surfaces maps which give the spatial variation of the transient temperature in the slabs is very important because it allows monitoring the mode and the 
intensity of the heat transfer during the process.

The iso-surfaces map shows the variation in temperature and therefore the intensity of cooling for different materials. The shape and the number of iso-surfaces in the map involve the intensity of cooling.

Histories of transient temperatures of different faces for the different alloys are plotted in some curves. Very rapid falls in temperature at the upper face of all materials are observed. These falls differ over time and by the form from one material to another. On the other hand, temperature drops are relatively slow on the lower face for all materials with suitable slopes.

The curves of variation of heat flux for each side of slabs for the different materials show high surface flux densities for the upper faces and very lower for the lower faces. The most important heat flux is that of the iron alloy, then the aluminum alloy, then the other materials.

\section{REFERENCES}

[1] Sasaki, K., Suiting, Y., Kawasaki, M. (1979). Heat transfer in spray cooling on hot surface. The Iron and Steel Institute of Japan, Tetsu to Hagane, 65(1): 90-96. https://doi.org/10.2355/tetsutohagane1955.65.190

[2] Grissom, W.M., Wierum, F.A. (1981). Liquid spray cooling of a heated surface. International Journal of Mass Transfer, 24(2): 261-271. https://doi.org/10.1016/00179310(81)90034-X

[3] Bamberger, M., Prink, B. (1986). Determination of heat transfer coefficients during water cooling of metals. Material Science and Technology, 2(4): 410-415. https://doi.org/10.1179/mst.1986.2.4.410

[4] Mudawar, I., Valentine, W.S. (1989). Determination of the local quench curve for spray-cooled metallic surfaces. Journal of Heat Treating, 7: 107-121. https://doi.org/10.1007/BF02833195

[5] Ito, T., Takata, Y., Moussa, M.M.M. (1992). Studies on the water cooling of hot surfaces: Analysis of spray cooling in the region associated with film boiling. ASME International Journal, 35(4): $\quad 589-598$ https://doi.org/10.1299/jsmeb1988.35.4_589

[6] Yao, C.S., Timothy, L.C. (2002). A general heat transfer correlation for impacting water sprays on hightemperature surfaces. Experimental Heat Transfer, 15(4) 207-219. https://doi.org/10.1080/08916150290082649

[7] Janik, M., Dyja, H. (2004), Modelling of threedimensional temperature field inside the mould during continuous casting of steel. Journal of Materials Processing Technology. 157-158: 177-182. https://doi.org/10.1016/j.jmatprotec.2004.09.026

[8] Labergue, A., Gradeck, M., Lemoine, F. (2005). Comparative study of the cooling of a hot temperature surface using sprays and liquid jets. International Journal of Heat and Mass Transfer, 81: 889-900. https://doi.org/10.1016/j.ijheatmasstransfer.2014.11.018

[9] Alizadeh, M., Edris, H., Shafyei, A. (2006). Mathematical modeling of heat transfer for steel continuous casting process. International Journal of Iron \& Steel Society of Iran, 3(2): 7-16.

[10] Kim, J. (2007). Spray cooling heat transfer: The state of the art. International Journal of Heat and Fluid Flow, 28(4): 753-767. https://doi.org/10.1016/j.ijheatfluidflow.2006.09.003

[11] Wendelstorf, J., Spitzer, K.H., Wendelstorf, R. (2008)
Spray water cooling heat transfer at high temperatures and liquid mass fluxes. International Journal of Heat and Mass Transfer, 51(19-20): 4902-4910. https://doi.org/10.1016/j.ijheatmasstransfer.2008.01.032

[12] Issa, R.J. (2009). Multiphase Spray Cooling Technology in Industry. Advanced Technologies, Kankesu Jayanthakumaran (Ed.). Intech Open. https://doi.org/10.5772/8217

[13] Panão, M.R.O., Moreira, A.L.N. (2009). Intermittent spray cooling: A new technology for controlling surface temperature. International Journal of Heat and Fluid Flow, 30(1): 117-130. https://doi.org/10.1016/j.ijheatfluidflow.2008.10.005

[14] Zhao, R., Cheng, W.L., Liu, Q.N., Fan, H.L. (2010). Study on heat transfer performance of spray cooling: Model and analysis. Heat Mass Transfer, 46: 821-829. https://doi.org/10.1007/s00231-010-0632-4

[15] Moreira, A.L.N., Panao, M.R.O. (2011). Spray-Wall Impact. In: Ashgriz N. (eds) Handbook of Atomization and Sprays. Springer, Boston, MA. https://doi.org/10.1007/978-1-4419-7264-4_21

[16] Yan, Z., Zhao, R., Duan, F., Wong, N.T., Toh, K.C., Choo, K.F., Chan, P.K., Chua, Y.S. (2011). Spray Cooling. Phase Change and Numerical Modeling, InTechopen. https://doi.org/10.5772/21076

[17] Gradeck, M., Labergue, A., Baillard, C., Maigrat, G., Lebouché, M. (2013). Refroidissement par pulvérisation - expériences et modèles. 21è Congrès Français de Mécanique, 26(30): 1-6.

[18] Hrabovský, J., Chabičovský, M., Astrouski, I., Kotrbáček, P. (2015). The heat transfer coefficient at discontinued water spray cooling. 5th Conference, 3rd Metal 2015 Brno, Czech Republic.

[19] Liang, G., Mudawar, I. (2017). Review of spray cooling - Part 1: Single-phase and nucleate boiling regimes, and critical heat flux. International Journal of Heat and Mass Transfer, 115(Part A): 1174-1205. https://doi.org/10.1016/j.ijheatmasstransfer.2017.06.029

[20] Gao, X., Li, R. (2018). Spray impingement cooling: The state of the art. Advanced Cooling Technologies and Applications. https://doi.org/10.5772/intechopen.80256

[21] Kabbir, A., Riffat, A., Muhammad, I.M., Sami, I.S., Kiseong, K. (2019). Impacts of different parameters on spray cooling of copper alloy B14. Annales de Chimie Science des Matériaux, 43(5): 281-286. https://doi.org/10.18280/acsm.430501

[22] Kyriopoulos, O., Roisman, I.V., Roisman, G.T., Stephan, P., Tropea, C. (2008). Dynamics of a liquid film produced by spray impact onto a heated target. 22th Int. Conf. on Liquid Atomization and Spray System. Como Lake, Italy, pp. 1-7.

[23] Elguerri, M. (2020). 3D transient heat transfer simulation of spray cooling on titanium alloy slab. Journal of Engineering Science, 64(2-4): 216-224. https://doi.org/10.18280/ti-ijes.642-414

[24] Breitenbach, J., Roisman, I.V., Tropea, C. (2018). From drop impact physics to spray cooling models a critical review. Experiments in Fluids, 59: 55. https://doi.org/10.1007/s00348-018-2514-3

[25] Elguerri, M. (2014). Aspects hydrodynamiques lors d'un croisement jets d'eau sous buses et influences de l'intensité du transfert thermique. PHD Thesis. Mechanical Engineering Department, Sciences and Technology University, Oran, Algeria. 
[26] Bratuta, E.G., Ivanowsky, A.Y. (1982). Intensification of heat and mass transfer during cooling by dispersed fluids. Energa - Machinotroenia, 33: 98-101.

[27] Nayak, S.K., Mishra, P.C., Parashar, S.K.S. (2016) Influence of spray characteristics on heat flux in dual phase spray impingement cooling of hot surface. Alexandria Engeneering Journal, 55(3): 1995-2004. https://doi.org/10.1016/j.aej.2016.07.015

[28] Bhatt, N.H., Raj, R., Lily, Varshney, P., Pati, A.R., Chouhan, D., Kumar, A., Munshi, B., Mohapatra, S.S (2017). Enhancement of heat transfer rate of high mass flux spray cooling by ethanol-water and ethanoltween20-water solution at very high initial surface temperature. International Journal of Heat and Mass Transfer, 110: 330-347. https://doi.org/10.1016/j.ijheatmasstransfer.2017.02.094

[29] Tenzer, F.M., Roisman, I.V., Tropea, C. (2019). Fast transient spray cooling of a hot thick target. Journal of Fluid Mechanic, 881: 84-103. https://doi.org/10.1017/jfm.2019.743

[30] Moriyama, A., Araki, K., Yamagami, M., Mase, K (1988). Local Heat-transfer coefficient in spray cooling of hot surface. Transactions of the Iron and Steel Institute of Japan, 28(2): 104-109. https://doi.org/10.2355/isijinternational1966.28.104

[31] Ciofalo, M., Caronia, A., Di Liberto, M., Puleo, S. (2006). On the derivation of the boiling curve in spray cooling from experimental temperature. International Heat Transfer Conferences, Sydney.

[32] Ondrouskova, J., Luks, T., Horsky, J. (2012). Nozzle cooling of hot surfaces with various orientations. EPJ Web of Conferences, 25(01063): 1-10. https://doi.org/10.1051/epjconf/20122501063

[33] Stetina, J., Kavička, F., Mauder, T., Klimeš, L., Masarik, M., Šaňa, Z. (2012). Optimization of secondary cooling in order to achieve higher surface temperatures at the slab unbending point. Metal 2012 Conferences, Brno, Czech Republic.

[34] Malinowski, Z., Telejko, T., Hadała, B., Cebo-Rudnicka, A., Szajding, A. (2014). Dedicated three dimensional numerical models for the inverse determination of the heat flux and heat transfer coefficient distributions over the metal plate surface cooled by water. International Journal of Heat and Mass Transfer, 75: 347-361. https://doi.org/10.1016/j.ijheatmasstransfer.2014.03.078

[35] Pati, A.R., Lily, Behera, A.P., Munshi, B., Mohapatra, S.S. (2017). Enhancement of heat removal rate of high mass flux spray cooling by sea water. Experimental Thermal and Fluid Science, 89: 19-40. https://doi.org/10.1016/j.expthermflusci.2017.07.012

[36] Landers, B.D., Disimile, P.J., Toy, N. (2017). The fluid thermal field over a flat heated disk. International Journa of Heat and Technology, 35(4): 799-805. https://doi.org/10.18280/ijht.350415

[37] Cebo-Rudnicka, A., Malinowski, Z. (2019). Identification of heat flux and heat transfer coefficient during water spray cooling of horizontal copper plate. International Journal of Thermal Sciences, 145: 106038. https://doi.org/10.1016/j.ijthermalsci.2019.106038

[38] Tenzer, F.M. (2020). Heat transfer during transient spray cooling: An experimental and analytical study. Dr Thesis, Darmstadt. https://doi.org/10.25534/tuprints-00011344

\section{NOMENCLATURE}

$\begin{array}{ll}\mathrm{C} & \text { Specific heat, } \mathrm{J} \cdot \mathrm{kg}^{-1} \cdot \mathrm{K}^{-1} \\ \mathrm{P} & \text { Pressure } \\ \mathrm{Q} & \text { Heat quantity, W } \\ \mathrm{T} & \text { Temperature, K } \\ \mathrm{G} & \text { Liquide mass flow rate, } \mathrm{kg} \cdot \mathrm{s}^{-1} \cdot \mathrm{m}^{-2} \\ \mathrm{H} & \text { Heat transfer coefficient, W. } \mathrm{m}^{-2} \mathrm{~K}^{-1} \\ \mathrm{n} & \text { Normal surface orientation } \\ \mathrm{t} & \text { Time, } \mathrm{s} \\ \mathrm{q}^{\prime \prime} & \text { Heat flux, W. } \mathrm{m}^{-2} \\ \mathrm{x}, \mathrm{y}, \mathrm{z} & \text { Space variables, } \mathrm{m}\end{array}$

\section{Greek symbols}

$\begin{array}{ll}\sigma & \text { Boltzmann } \\ \varepsilon & \text { Emissivity } \\ \mathrm{P} & \text { Density, Kg } \\ \lambda & \text { Heat conductir } \\ \partial & \text { Differential } \\ \Delta & \text { Difference } \\ \text { Subscripts } & \\ & \\ 0 & \text { zero } \\ \mathrm{D} & \text { dynamic } \\ \text { a } & \text { air } \\ \text { ebu } & \text { ebullition } \\ \text { inf } & \text { inferior } \\ \text { ini } & \text { initial } \\ \text { sat } & \text { saturation } \\ \text { sur } & \text { surface } \\ \text { up } & \text { upper } \\ \text { amb } & \text { ambient } \\ \text { conv } & \text { convection } \\ \text { max } & \text { maximum } \\ \text { radi } & \text { radiation } \\ \text { spra } & \text { spray } \\ \text { " } & \text { surface }\end{array}$

